All letters must be typed with double spacing and signed by all authors.

No letter should be more than 400 words.

For letters on scientific subjects we normally reserve our correspondence columns for those relating to issues discussed recently (within six weeks) in the BMF.

We do not routinely acknowledge letters. Please send a stamped addressed envelope if you would like an acknowledgment.

Because we receive many more letters than we can publish we may shorten those we do print, particularly when we receive several on the same subject.

\section{How the NHS responds to a disaster}

SIR, - The night of Sunday 8 January 1989 should have been a quiet one for the Queen's Medical Centre, Nottingham. The City Hospital was on "surgical take" so we would have expected to take in only those admitted through our accident and emergency department. I was the general surgeon on duty at the Queen's and, at about 9 o'clock in the evening, was reading an article in the Sunday Times in which the leaked Cabinet review was so critical of consultant staff. My telephone rang and a very quiet and restrained telephonist said, "We have a major disaster."

It took us some 15 minutes to reach the hospital, by which time the stream of ambulances had begun to arrive. In the accident and emergency department were our three consultants and a host of junior staff of all disciplines, enough to provide each of the injured with several doctors. The injured were numbered on arrival, for many were unconscious and the remainder too shocked to speak, their clothing torn and without possessions with which to identify them; it seemed strange to check the cross matched blood for "Patient 1405."

The major disaster plan was working well. Two wards had been evacuated and were ready to accept the injured, while the intensive care unit was gathering staff and preparing its complex machinery. At 10 o'clock I went to the theatre unit and found the theatre manager there. He told me he had eight theatres fully staffed and ready. Within minutes my first crushed abdomen and chest was coming into theatre.

At no time did I see any shortage of medical staff. One patient, his face crushed beyond belief, needed specialist care and within minutes two consultant surgeons, dental and ear, nose, and throat, were examining him and planning his treatment. Most of the injuries were skeletal, in particular leg and spine fractures, and all our nine consultant orthopaedic surgeons, with their junior staff, were there before midnight. We had so many anaesthetists that there were two with every patient in theatre.

I was pleased to read the words of the BMF's editor, "the medical care was exemplary." Indeed, I believe it to have been so, but I know that it could not have been so without the work of the rest of the hospital staff. Ward F19 was evacuated to provide room for the casualties and I saw staff midwives busy pushing patients in their beds over to the east block. I went into theatre and found my operating department assistant there; he said, "I heard it on the telly, so I thought I had better come." Anything we needed for the casualties seemed always to be to hand: crystalloid and colloid infusions and blood cross matched seemingly in minutes for the drips, and no doubt this was due to the laboratory, blood bank, and pharmacy staff being there in large numbers. We had porters and our engineers. Again they said, "I heard it on the telly, so I came in." Radiographers, normally in short supply on a Sunday evening, were there and were too many to count, and moving among the critically injured were our padres of all denominations. The catering staff provided an endless supply of coffee, fruit juice, and sandwiches when needed; a kindly lady said to me at 2 in the morning, "Do sit down and let me get you something to eat, you look so tired." An administrative lady was moving around trying to identify names of the injured. The nursing staff were truly magnificent. The intensive care unit appeared to have its full complement of both day and night sisters and staff nurses all quietly and efficiently going about their duties. On ward F19 I counted seven ward sisters apart from the usual nursing staff, all busily seeing to the injured.

The injuries were horrific. Compound leg fractures, with feet almost detached at the ankle, appalling cervical and lumbar spinal fractures, crushed chests with multiple rib fractures, haemothoraces, but few abdominal injuries. Some patients were unconscious, and often paralysed, and virtually all were deeply shocked. Throughout the night all the teams I have described worked skilfully and gave devoted care to the very best of their ability. The abdominal injuries were few, and by $330 \mathrm{am}$ I was no longer needed. As I went away, I realised that that one sentence had been repeated so of ten that it summarises the response of our hospital staff that night - "I heard it on telly, so...."

Queen's Medical Centre,

DAVID W DALY

Nottingham NG5 $4 \mathrm{FB}$

1 Anonymous. Editor's choice. Br. Hed f 1989;298. 1+ January.

\section{Radiotherapy's second setback}

SIR, - The emotive language in Dr Richard Smith's leading article (potentially dangerous treatment, may do as much harm ... as the overtreatment . . . of patients . . . in Exeter) ${ }^{1}$ will confuse the issue. The proposed machine at St Thomas's Hospital, London, is to be similar to that at Clatterbridge, about which Dr Smith remarks: "With the advanced care available at Clatterbridge there is no reason to think that any patient will come to harm." So why will similar treatment at St Thomas's be so dangerous?

The serious morbidity encountered in the neutron therapy trials at Hammersmith and Edinburgh was due to several factors. The maximum dose of neutrons that could be given safely, particularly in the larynx, was not known; many of the patients had advanced disease, which is difficult to control and had already caused extensive damage; and the neutron beams were of fairly low energy.

The last point needs a little more comment. The dose distributions obtainable were intermediate between those of $200 \mathrm{kV} x$ rays and cobalt $\gamma$ rays. The new cyclotron at Clatterbridge is equivalent in this respect to a modern high energy $x$ ray machine working at 6-8 $\mathrm{MeV}$. The higher energy also modifies the biological response in that the radiation quality is less extreme relative to that of $x$ rays. Experimental results in animals have already shown that late morbidity in some tissues will be much less than that occurring after treatment with lower energy neutrons. ${ }^{2}$ At the Fermilab near Chicago neutron therapy with a beam similar to that at Clatterbridge began in 1976 and is still continuing; if late morbidity were comparable with that in the trials at Hammersmith and Edinburgh the treatments would have ceased by now. But the types of disease treated there are different from those included in the old British trials: promising results have been obtained in non-epidermoid cancers of the head and neck (mostly salivary glands and nasal sinuses), secondary neck nodes, adenocarcinoma of the prostate, and sarcomas.

All neutron therapy trials, without exception, have confirmed the favourable results obtained in treating salivary gland tumours. ${ }^{5}$ It is difficult to believe that there are no other tumours that will respond similarly. With the new equipment giving good dose distributions it should be possible to identify other suitable tumours that can be treated without severe morbidity, perhaps using better treatment schedules. To condemn a machine similar to that at Clatterbridge on the basis of severe morbidity at Hammersmith and Edinburgh would be like condemning modern radiotherapy on the basis of the severe morbidity, such as fractures of the femoral neck, that have occurred so often after treatment with $200 \mathrm{kV} x$ rays.

London W'11 4QP

D K BEWLEY

I Smith R. Radiotherapy's second setback. Br Med f 1988:297 1625-6. 24-31 December.

2 Joiner MC. A comparison of the effects of $p(62) \mathrm{Be}$ and $\mathrm{d}(16) \mathrm{Be}$ neutrons in the mouse kidnev. Radiother Oncol 1988;13: $211-2$

3 Cohen L, Hendrickson FR, Parvathy DK, et al. Clinica evaluation of neutron beam therapy. Cancer 1985;55:10-7.

4 Errington RD. Fast neutrons in radiotherapy. Lancet 1986;ii:38.

5 Laramore GE. Fast neutron radiotherapy for inoperable salivar gland tumors: is it the treatment of choice? Int $\mathcal{O}$ Radiat Oncol Biol Phys 1987;13:1421-3.

SIR, - No one can doubt that Dr Mary Catterall's enthusiasm for neutron therapy' has at least been partly responsible for the drive to provide a second high energy cyclotron in the United Kingdom. However, there is little evidence to support this enthusiasm for a treatment which to date has been shown to be of benefit only in some rare tumours. 
As scientists we have open minds about the role of neutrons in the treatment of cancer. We await with interest the results of properly conducted clinical trials currently being carried out at Clatterbridge Hospital and elsewhere. These have been carefully designed to evaluate the role of neutrons and protons and to assess the morbidity associated with treatment.

Dr Catterall does not address the problems of neutron associated morbidity, whereas for us this is a major concern. Increased normal tissue damage and excess mortality have been described in studies of neutron therapy ever since the first investigations carried out by Stone and Larkin in the late 1930s. In an independent analysis of neutron therapy trials carried out at the Hammersmith Hospital and in Edinburgh in patients with cancers of the head and neck region a statistically significant increased morbidity rate was noted in those treated by fast neutrons ${ }^{2}$; of the 40 patients treated in the series who were assessed as being free of local disease at death $11(28 \%)$ died as a direct result of their treatment. In addition, a significantly higher proportion of neutron treated patients died of what was judged to be intercurrent disease when their primary tumours were controlled. It has been said that fast neutrons are the treatment of choice for certain types of tumour, including maxillary antral lesions and soft tissue sarcomas. However, in the publication by Catterall et al in 1984 a serious complication rate of $28 \%$ was found in patients with tumours of the maxillary antrum treated by neutrons.' These complications included brain necrosis and blindness, and it is questionable whether this level of complication is acceptable. More recently, a report has appeared from the Royal Marsden Hospital presenting the results of a trial of the treatment of soft tissue sarcomas carried out in collaboration with Dr Catterall at the Hammersmith Hospital. ${ }^{+}$In this study the normal tissue complications of those treated by fast neutrons was so severe that the trial was stopped. The argument has been made that the better dose distributions of neutrons that would be obtained using high energy beams will overcome the problems of morbidity. This remains to be proved and is one of the end points of the continuing trials. Indeed, some reports from centres in the United States using higher energy beams have also reported increased morbidity.

In view of these reports it would be improper to give patients routine treatment with neutron therapy until the trials in progress at Clatterbridge and elsewhere have shown that neutron therapy is no more hazardous than and at least as efficacious as currently accepted forms of treatment.

\section{RAYMOND HOFFENBERG WALTER BODMER}

$S$ ARNOTT

NIGEL KEMP

\section{N M BLEEHEN}

United Kingdom Cordinating Committee on Cancer Research. London WIN 4AL

1 Catterall M. Radiotherapy's second setback. Br Med 7 1989;298 113. (14 January.)

2 MRC Neutron Therapy Working Group. A comparative review of the Hammersmith (1971-1975) and Edinburgh (1977-1982) neutron therapy trial of certain cancers of the oral cavity, neutron therapy trial of certain cancers of the oral cavity,
oropharynx, larynx and hypopharynx. Br $\mathcal{F}$ Radiol 1986;57: orophary

3 Catterall M, Blake PR, Rampling RP. Fast neutron treatment as an alternative to radical surgery for malignant tumours of the an alternative to radical surgery for $\mathrm{m}$

+ Glaholm J, Harmer C. Soft-tissue sarcoma: neutrons versus protons for post-operative irradiation. Br $\mathcal{J}$ Radiol 1988;61 829-34.

5 Cohen L, Hendrickson F, Mansell J, et al. Response of sarcomas of bone and soft tissue to neutron beam therapy. Int $\mathcal{Y}$ Radial Oncol Biol Phys 1984;10:821-4.

SIR, - As someone with some knowledge of neutron therapy I read Dr Richard Smith's editorial with interest.' Not being privy to the evidence put forward for the St Thomas's Hospital cyclotron I cannot comment on its merits or otherwise.
However, cancer and health money are emotional subjects and will remain so. In the consideration of such issues it is most important to remain as dispassionate as possible. In not doing so-for example, talking of "a dangerous white elephant" - Dr Smith does not do himself or the $B M \mathcal{F}$ justice.

In the same vein it is important to consider some of the issues raised in the editorial. For instance, there is inconsistency in the remarks about danger to patients. Twice neutron therapy is labelled as possibly dangerous or dangerous and once we are assured that there is no reason to think that any patient will come to harm. Perhaps reasons for these contradictions should be given, since such unclear assertions can be misconstrued.

Secondly, it is important to remember that the types of patients in the Hammersmith and Edinburgh series were not the same, and indeed those patients with head and neck cancer for whom neutron therapy might have been of value were not treated in the Edinburgh study.

Thirdly, Dr Smith does less than justice to neutron therapy in glandular cancers of the head and neck. About 300 patients have been reported in total with about $65 \%$ total control. This is more than twice that expected of other forms of therapy for such disease.

Fourthly, assertions are made that there is no necessity for another unit and patients who need neutron therapy could be treated at Clatterbridge. No evidence is given either way for this. Has the likely patient burden in England been examined? If so, did this include ophthalmic and other tumours which might be treated with protons? It would be helpful to know.

Whatever our views on such matters, we must approach them in a most careful and objective way. We owe it to our patients.

Mersey Regional Centre for Radiotherapy and Oncology

Merseyside L63 4JY

I Smith R. Radiotherapy's second setback. Br. Med J 1988;297: 1625-6. 24-31 December.

\section{NHS: a time to choose}

SIR, - Who did Dr Tony Smith and his anonymous cothinkers consult before declaring that health services fully funded by taxes on the Swedish model or by insurance on the Franco-German model "are, we believe, equally acceptable to patients and the health professions"? Has he, or have they, never heard of the clinical differences between the continuity and proactive care possible for registered populations and the episodic, fragmented, uncritical, and inflated proceduralism inevitable in reimbursed insurance systems? Or that France and the Federal Republic of Germany remain virtual no go areas for self critical, population oriented general practice? Or that in both France and the German Federal Republic insurance systems are running into unsustainable problems of cost inflation?

The happy fact that Smiths from Adam to Tony often fail to appreciate is that many forms of value production are too civilised and sophisticated to do well on sticks, carrots, or a combination of the two. Among these are all forms of education, many kinds of farming, serious music, painting, theatre, architecture, gardening, bee keeping, and medical care. Beyond a not outrageously high level of income and security (which nearly all doctors in the United Kingdom now have), the satisfaction of effective work elegantly (that is, economically) performed is more important to most doctors than earnings. If Dr Smith must throw a lifebelt to a government still unable to produce a policy acceptable to both itself and its voters this is the one he should choose, not clinically obsolete fee paid insurance; but it does need some imagination to adapt this to a practical policy, and imagination is not a currently approved virtue.

As for acceptability to patients this calls for even more caution. If apparently responsible politicians offer the attractive but inherently unworkable combination of lower taxes and higher civilisation it is not surprising if voters at first believe them. Eventually, however, a choice must be made between personal greed and shared civilisation. It really is time to choose, and not to fudge the choice with obsolete remedies; we and the Swedes were right the first time.

JULIAN TUDOR HART

Glyncorrwg, West Glamorgan SA13 3BL

1 Smith T. NHS: a time to choose. Br Med $\mathcal{F}$ 1989;298:1-2. (7 January.)

SIR,-Dr Tony Smith's editorial' is excellent and courageous. Unfortunately, there is one particular stumbling block to the much needed rethinking of the method of funding health services in Britain that will be difficult to overcome-any British government is extremely unlikely to admit publicly that we have been left behind by other countries in northern Europe, especially on a subject as sensitive as health care.

But that is the reality. I am now convinced from my own medical and family connections that ordinary people in France, Germany, Belgium, and Holland get a better service than those in Britain. They are not financially embarrassed, and there is not the unpleasant separation between private patients and others. Our National Health Service is claimed to be "a good buy" in relation to what is spent on it. To wait two years or more for a hip replacement is a buy that would not be tolerated in other European countries.

JOHN GARFIELD

Wessex Neurological Centre,

Southampton General Hospital

Southampton $\mathrm{SO} 4 \mathrm{XY}$

1 Smith A. NHS: a time to choose. Br Med $\mathcal{F}$ 1989;298:1-2.

(7 January.)

SIR,-The core presupposition of Dr Tony Smith's editorial' is unproved. On what grounds, other than that the proposition is oft repeated, are we impelled to believe that the NHS is underfunded? Dr Smith brings forward the usua examples of poor hospital stock, ward closures, allegedly excessive waiting lists, and the contraction of academic medicine but nowhere convinces that these are a consequence of underfunding rather than long term poor management. Furthermore, argument of the case by appeal to comparison of our spending with that in other countries is spurious as it can be posited that countries that spend more are profligate in their use of resources.

The argument becomes superficially more attractive when the countries that spend more are shown to have a lower mortality (Dr Smith states that Scandinavian infant mortality rates reflect this). This, however, ignores the fact that expenditure on health (beyond basic public health measures and simple preventive procedures) has never been shown to have an inverse monotonic relation to overall population mortality; the lack of such a relation is implicit in the thesis of $\mathrm{McKeown}^{2}$ and is supported by my own work, ${ }^{3+}$ among others. I am not, however, attempting to deny that modern medical services have considerable benefit in reducing suffering for many and extending life for some, but we have inadequate knowledge of both the extent of treatable morbidity in the population and the effectiveness and value for money of the services on offer. Hence we have too few grounds for any rational debate about the adequacy of 